\title{
Sistema de indicadores educacionais no acompanhamento e avaliação de políticas públicas
}

\author{
JOSÉ GONÇALVES MOREIRA NETO*
}

\section{RESUMO}

Este artigo apresenta os resultados do sistema de indicadores desenvolvido pela Secretaria de Educação Continuada, Alfabetizaçáo e Diversidade (Secad) para o acompanhamento do Programa de Educação para a Diversidade e Cidadania (Programa PPA 1377), no período de 2002 a 2006. Foram utilizadas como fontes primárias de dados o Censo Escolar da Educação Básica, realizado pelo Instituto Nacional de Estudos e Pesquisas Educacionais Anísio Teixeira (Inep) e a Pesquisa Nacional por Amostra de Domicílios (Pnad), do Instituto Brasileiro de Geografia e Estatística (IBGE). Com base na análise dos resultados, foi possível constatar a diminuiçáo gradativa da desigualdade educacional nos diversos públicos que compóem o tema diversidade (indígenas, populaçáo do campo, pobres, negros e mulheres), impulsionada principalmente pela evolução de indicadores educacionais relacionados à conclusão do ensino médio e pela freqüência ao ensino médio e superior.

Palavras-chave: desigualdades educacionais, avaliação, políticas públicas, dados estatísticos, educação.

* Consultor Estatístico da Secretaria de Educação Continuada, Alfabetização e Diversidade (Secad) (jose.neto@mec.gov.br). 


\section{RESUMEN}

Este artículo presenta los resultados del sistema de indicadores desarrollados por la Secretaría de Educación Continua, Alfabetización y Diversidad (Secad) para el seguimiento del Programa de Educación para la Diversidad y la Ciudadanía (Programa PPA 1377), en el período 2002-2006. Como fuentes primarias de datos se han utilizado el Censo Escolar de Educación Básica, realizado por el Instituto Nacional de Estudios y Encuestas Anísio Teixeira (Inep) y la Encuesta Nacional de Hogares (Pnad), del Instituto Brasileño de Geografía y Estadística (IBGE). El análisis de los resultados constató una reducción gradual de la desigualdad educativa en los diferentes públicos que componen la temática de la diversidad (aborígenes, población del campo, pobres, negros y mujeres), impulsada principalmente por la evolución de indicadores educativos relacionados a la finalización de la enseñanza media y por la mayor asistencia a la enseñanza media y superior.

Palabras clave: desigualdades educativas, evaluación, políticas públicas, datos estadísticos, educación.

\section{ABSTRACT}

This article presents the results attained by the Educational Indicator System, which was developed by Secad in order to keep track of the Education Program for Diversity and Citizenship (PPA Program 1377) between 2002 and 2006. To build the system it was used available data from the School Census, carried out by Inep (National Institute of Studies and Research in Education Anisio Teixeira) and from Pnad, carried out by IBGE (Brazilian Institute of Geography and Statistics). The results showed a gradual decrease in educational inequality of specific groups such as native population, country residents, the poor, blacks and women. The main cause for this decrease can be attributed to the evolution of educational indicators related to high school completion and attendance and also to college or university attendance.

Keywords: educational inequalities, evaluation, public policies, statistical data, education. 


\section{INTRODUÇÃO}

O Brasil tem assistido nos últimos anos a um movimento de expansão das ações de acompanhamento e avaliação das políticas públicas desenvolvidas no país, principalmente no âmbito do governo federal. A utilização de recursos públicos em açóes que não têm seu impacto devidamente mensurado, passando por uma minuciosa análise de custo-efetividade tem, cada vez mais, perdido espaço na administração pública federal. Órgãos como o Tribunal de Contas da União e a Controladoria Geral da Uniáo, aliados à criação de unidades especializadas dentro da estrutura organizacional do executivo federal, têm auxiliado na construçáo de uma cultura de avaliação e contribuído para a correta e efetiva aplicação dos recursos públicos.

Neste contexto, a utilização de índices sintéticos e indicadores relacionados aos programas sociais desenvolvidos têm ganhado espaço e servido de instrumentos para balizar a distribuição de recursos, caminhando para constituírem-se em ferramenta de monitoramento da política pública e em critério de alocação global do gasto público no país. No entanto, não esporadicamente, surgem polêmicas acerca do debate sistema de indicadores versus indicadores sintéticos, oferecendo-nos argumentos num e noutro sentido.

Para Saltelli et al. (2004), indicadores sintéticos aumentam a quantidade de dados, porque são necessários dados para cada um dos subindicadores e para uma análise estatística significativa. Jannuzzi (2002) critica o excesso na aplicação desse tipo de indicador, alertando para o risco de substituição do conceito que se quer medir pela medida. Ryten (2000) julga que as agências oficiais de estatística (AOE) não devem auferir seu "selo de legitimidade" publicando simples números que ainda careçam de uma sólida base teórica.

Por outro lado, Saltelli et al. (2004), contrapondo-se aos argumentos críticos, lista algumas vantagens da utilização de indicadores sintéticos:

- $\quad$ podem ser usados para sumarizar questóes complexas ou multidimensionais, com o intento de apoiar tomadores de decisão;

- por oferecerem uma visão geral, pode ser mais fácil interpretá-los do que tentar encontrar uma tendência com muitos indicadores separados;

- $\quad$ podem ajudar a reduzir o tamanho de uma lista de indicadores e a atrair a atençáo do público, ao fornecer um número resumido com o qual se pode comparar o desempenho de vários países, Estados, municípios e seu progresso no decorrer do tempo. 
Mais especificamente no campo da educação, Scandar Neto, Silva e Jannuzzi (2006) dizem:

Os indicadores sintéticos permeiam o campo programático da Educação. Sintomático neste sentido foi a situação vivenciada pelo Inep - órgão produtor e compilador das estatísticas educacionais do MEC - de ver-se compelido a dispor de um indicador sintético, construído a partir do amplo escopo temático de informaçóes coletadas no Censo Escolar, que pudesse refletir a qualidade e o desenvolvimento do sistema educacional brasileiro no âmbito municipal e viesse a subsidiar o processo de decisão e avaliação de políticas públicas educacionais. (p. 18)

A despeito da utilidade e características próprias de cada opção - sistemas de indicadores ou indicadores sintéticos - e de argumentos de natureza conceitual e metodológica, os autores ainda provocam:

Mas, afinal, qual a importância de se dispor de medidas-síntese e sua utilidade para gestores de programas sociais ou educacionais? Não seria mais útil um sistema com diversos indicadores, referindo-se a várias dimensōes da realidade social, mais adequado para elaboração de um diagnóstico profundo mais rico e aprofundado? Mas como apreender esta multidimensionalidade do social para obter uma avaliação integrada das condiçôes de vida, da situação educacional ou do estágio de desenvolvimento sustentável alcançado? Como tomar uma decisão acerca de áreas prioritárias e atender os públicos-alvo a atingir, considerando um conjunto amplo de indicadores simultaneamente? (p. 18)

Amparados nas idéias de Latour (2000), que sugerem a especificação de um sistema mais abrangente de indicadores (mecanismo de ampliação de Latour), para que se possa buscar posteriormente a construção de uma medida-resumo (o mecanismo de redução do autor), Scandar Neto, Silva e Jannuzzi (2006) propóem e exemplificam a criação de sistema de indicadores no que a síntese ganha um sentido de "organização do olhar", uma vez que permite focar a atenção nos indicadores que realmente importam. Dessa forma, procura-se romper a dicotomia indicador sintético versus sistema de indicadores, partindo-se da premissa de que a síntese náo pode prescindir do sistema.

Utilizando essa linha metodológica, a Secad, vinculada ao Ministério da Educação, promoveu e estimulou, em 2005, a realização de estudos sobre indicadores educacionais para a diversidade, no intuito de compor uma primeira proposta de 
um sistema de indicadores para monitoramento baseado em resultados. Essa ação reuniu especialistas e representantes da sociedade civil e do Ministério da Educação para discutir e implementar um sistema de indicadores de resultado que pautassem os diversos programas e açóes que essa Secretaria vem executando desde a sua criação em 2004, de acordo com os objetivos e competências estabelecidos em sua institucionalização.

É importante ressaltar que cabe à Secad coordenar e fomentar o planejamento e a implementação de políticas nacionais que visem à inclusão socioeducacional de setores da população historicamente marginalizados no país. Dessa forma, os trabalhos foram conduzidos com base em um elemento fundamental, que serve como critério para a determinação do conjunto de iniciativas da Secad no marco do Programa de Educação para a Diversidade e Cidadania, que foi a identificação e mensuração de desigualdades e assimetrias socioeducacionais, tais como: as desigualdades étnico-raciais, de gênero, identidade de gênero e orientação sexual, a assimetria entre a população do campo e a das áreas urbanas, a população indígena, a população remanescente de quilombos, a alfabetização e Educação de Jovens e Adultos, e outras populaçóes consideradas em situação de vulnerabilidade e risco social.

A intenção de transformar a escola - entendida como instituição, independentemente do nível de educação em que está inserida - em um locus transmutador das relaçóes sociais e promotor do conhecimento, em prol de uma sociedade mais igualitária e equânime, tem como um de seus pontos estruturantes o reconhecimento dos determinantes que impedem, ou pelo menos dificultam, o acesso e a permanência na escola, a trajetória de estudos e o sucesso nas atividades escolares, papel aqui desempenhado pelo sistema de indicadores desenvolvido.

Na seção 2, será apresentado um breve detalhamento sobre os indicadores utilizados e a obtenção de indicadores sintéticos. A seção 3 traz os resultados dos indicadores entre 2002 e 2006, e a seção 4 contém algumas considerações sobre o estudo em questão.

\section{METODOLOGIA}

A Secad iniciou, no último trimestre de 2005, no Programa 1377 do Plano Plurianual do governo federal (PPA) 2004-2007, denominado Educação para Diversidade e Cidadania, o processo de construção de um sistema de indicadores para monitoramento e avaliação, com a realização de uma oficina formada por seis Grupos de Trabalho (GTs), a saber: Educação Escolar Indígena, Açôes Educacionais 
Complementares, Educação do Campo, Gênero, Identidade de Gênero e Orientação Sexual, Educação Socioambiental, Diversidade étnico-racial.

$\mathrm{Na}$ primeira fase da oficina, os GTs se concentraram em duas tarefas principais. Em primeiro lugar, foi realizada uma análise que tinha como objetivo central avaliar a adequação das açóes do Programa 1377, de responsabilidade da Secad, presentes no PPA 2004-2007, em relação às demandas e necessidades reais explicitadas pelos participantes de cada um dos grupos.

Em segundo lugar, com base nas demandas e necessidades mencionadas no parágrafo anterior, os grupos de trabalho refletiram sobre os principais desafios, problemas e limitaçóes que os diferentes públicos-alvo enfrentam atualmente em termos da inclusão socioeducacional de grupos tradicionalmente excluídos das diversas etapas do sistema educacional. Para isso, uma importante tarefa foi a realização de um levantamento sintético das principais problemáticas - assim como a sua hierarquização - enfrentadas por esses segmentos da população.

$\mathrm{Na}$ segunda fase da oficina, após um período de recesso estabelecido para a reflexão acerca das conclusóes da primeira fase, a principal tarefa consistiu na discussão sobre indicadores que deveriam ser incluídos no sistema de indicadores. Para realizar essa tarefa, foi utilizada a mesma metodologia de trabalho dos GTs. Ao final da segunda fase, conseguiu-se estabelecer um conjunto significativo de indicadores que possuíam como principal virtude expressar claramente as problemáticas e os desafios a serem enfrentados. Por outro lado, esse conjunto de indicadores também expressa a vocação democrática e participativa da Secad, no sentido de levar em consideração as diversas demandas dos representantes da sociedade civil.

Os principais resultados da oficina precisaram ser complementados com uma análise técnica sobre a viabilidade de estruturar um sistema de indicadores para monitoramento e avaliaçáo baseado em resultados, compatibilizando essa viabilidade técnica com as demandas e as reflexóes explicitadas durante as discussóes. Nesse sentido, fez-se necessário contemplar uma sistematização metodológica que incluísse três aspectos importantes a serem abordados:

a) a disponibilidade e a sustentabilidade, em longo prazo, de bases de dados que permitam a estabilidade do sistema de indicadores. Essa disponibilidade e sustentabilidade devem levar em consideração também um critério de custo e benefício, que permita que esse sistema seja também eficiente em termos de sua viabilidade financeira;

b) a definição rigorosa dos indicadores que integrarão o sistema de indicadores deverá guardar estreita relação com o cumprimento das demandas e tarefas, 
que, por sua vez, devem permitir o alcance efetivo das metas estabelecidas. Com efeito, é preciso estabelecer um nexo claro e sólido entre metas, indicadores, ações e programas. Nesse sentido, a literatura especializada (World Bank, 2000) fornece um embasamento conceitual de grande relevância em relação à determinação de indicadores de resultado que possam ser realmente afetados pelas açóes e programas a serem implementados em cada uma das áreas temáticas; e

c) o sistema de indicadores para monitoramento e avaliação na sua totalidade deve comportar indicadores que sejam coerentes, tanto em relação a cada um dos temas quanto em relação ao conjunto de temas que farão parte desse sistema.

Com base nas considerações anteriores, foram construídos seis índices sintéticos de igualdade para cada uma das dimensóes propostas (Educação Escolar Indígena, Educação no Campo, Açóes Educacionais Complementares, Diversidade ÉtnicoRacial e Igualdade de Gênero), sendo que a dimensão Gênero possui dois índices sintéticos, um para as mulheres e outro para os homens. Todas essas etapas, bem como a base conceitual e a formalização do $S M \& A-R$, são descritas com mais detalhes em Blanco Cossío et al. (2006).

Como o objetivo é mensurar e avaliar os progressos no combate à redução das desigualdades socioeducacionais, decidiu-se assumir como único instrumento de igualdade a razão entre um determinado indicador - calculado para o grupo-alvo - e o mesmo indicador para a população total. Em geral, praticamente todos os indicadores que compóem os índices sintéticos são expressos em porcentagens, exceto o número médio de anos de estudo.

Assim:

$\mathrm{I}_{(\mathrm{ij})}=$ Indicador $_{(\mathrm{j})} /$ Indicador (população total) $\quad 0 \leq \mathrm{I} \leq \infty$

Onde:

$\mathrm{I}_{(\mathrm{ij})}=$ Igualdade,

$\mathrm{i}=$ denota $\mathrm{o}$ indicador;

$\mathrm{j}=$ o público alvo.

Por outro lado, os índices sintéticos são a expressão de uma média aritmética simples dos indicadores de igualdade. Finalmente, cada Indicador de Igualdade é incorporado ao Índice Sintético de Igualdade em cada dimensão: 


$$
\mathrm{II}_{(\mathrm{ij})}=\sum \mathrm{I}_{(\mathrm{ij})} / \mathrm{N}
$$

Onde $\mathrm{N}$ = Número total de Indicadores de Igualdade em cada dimensão.

É importante ressaltar que as bases de dados utilizadas para o cálculo de tais indicadores foram a Pesquisa Nacional por Amostra de Domicílios (Pnad) do IBGE e o Censo Escolar - Inep/MEC.

\section{RESULTADOS DOS INDICADORES}

\subsection{O Índice de Igualdade da Educação Escolar Indígena (II-EEI)}

Esse índice é composto por três razões de igualdade entre a população indígena e a média nacional: porcentagem de escolas que funcionam em prédio escolar; porcentagem de matrículas de $5^{\mathrm{a}}$ a $8^{\mathrm{a}}$ séries do ensino fundamental em relação ao número total de matrículas nesse nível de ensino; e porcentagem de professores com ensino superior completo (licenciatura) nas séries iniciais do ensino fundamental.

O gráfico 1 apresenta a evolução do II-EEI de 2002 a 2006. Durante o período, verificou-se um crescimento de 9,49\% nesse índice, que passou de 0,419 em 2002 para 0,459 em 2006. Apesar desse aumento, observam-se baixos valores para o índice, o que caracteriza uma desigualdade latente entre os alunos indígenas quando comparados com os estudantes brasileiros (quanto mais próximo de 1 maior a igualdade).

É possível observar, ainda, que o crescimento mais expressivo do índice $(8,6 \%)$ se deu entre 2004 e 2005. Por outro lado, é importante mencionar a redução do IIEEI em 2003 e 2004 (-6,43\%).

Dentre os motivos identificados que mais contribuíram para o aumento do IIEEI no período 2002-2006 destacam-se a evolução do porcentual de matrículas de $5^{\mathrm{a}}$ a $8^{\mathrm{a}}$ séries do ensino fundamental em relação ao número total de matrículas nesse nível de ensino e o crescimento, em menor proporção, da porcentagem de professores com ensino superior completo (licenciatura), como pode ser visto do gráfico 2 .

Portanto, a evolução positiva desse índice pode ser explicada, basicamente, pela melhoria da razão de igualdade da porcentagem de matrículas de $5^{\mathrm{a}}$ a $8^{\mathrm{a}}$ séries do ensino fundamental em relação ao número total de matrículas nesse nível de ensino, que teve um acréscimo substancial de $26 \%$ no período em questão, passando de 0,38 em 2002 para 0,47 em 2006. Novamente, é importante ressaltar aqui que, mesmo diante dessa evoluçáo positiva, tais valores denotam profunda desigualdade e ainda se encontram distantes da eqüidade desejada. 
Gráfico 1 - Evolução do Índice de Igualdade Escolar Indígena - Brasil, 2002-2006

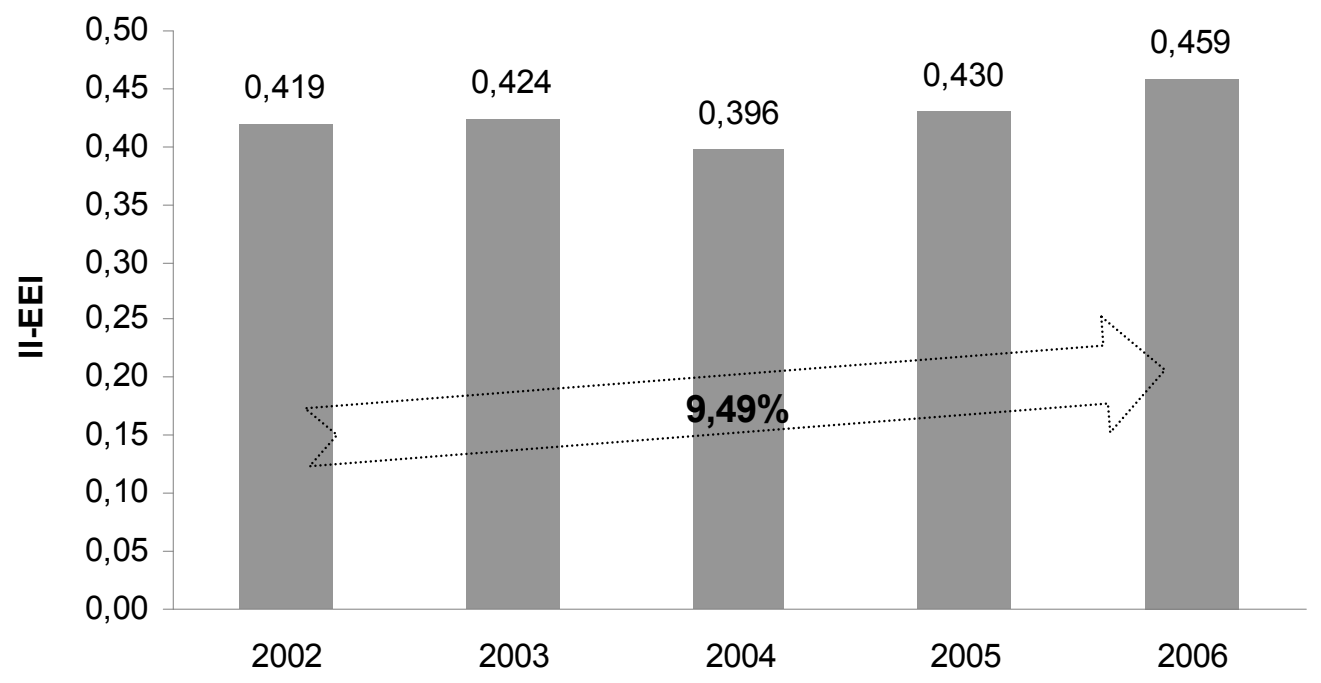

Fonte: Censo Escolar - MEC/Inep.

Gráfico 2 - Evolução dos componentes do Índice de Igualdade Escolar Indígena - Brasil, 2002-2006

$\%$ de matrículas de $5^{\mathrm{a}}$ a $8^{\mathrm{a}}$ séries do ensino fundamental sobre o número total de matrículas nesse nível de ensino

$\%$ de professores com superior completo (licenciatura) nas séries iniciais do ensino fundamental

$\%$ de escolas que funcionam em prédio escolar

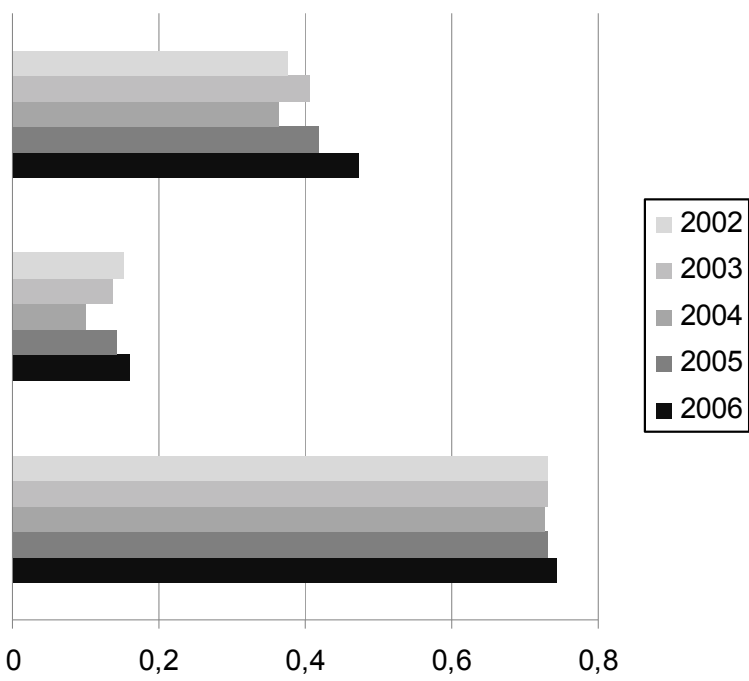

Fonte: Censo Escolar - MEC/Inep. 
Observando as tabelas 1 e 2, a seguir, constata-se que todos os indicadores educacionais para a populaçáo indígena, no período estudado, são piores do que aqueles referentes à população total, ilustrando a grande desigualdade existente. Exemplificando, podemos verificar que em 2006 aproximadamente $91 \%$ das escolas funcionavam em prédios escolares, ao passo que apenas $67 \%$ das escolas indígenas apresentavam tal característica. Cerca de $53 \%$ dos professores da primeira parte do ensino fundamental possuíam ensino superior (licenciatura) contra apenas 8,5\%

Tabela 1 - Evolução dos Indicadores Educacionais - 2002-2006 - População Total

\begin{tabular}{|c|c|c|c|c|c|c|}
\hline \multirow{2}{*}{ Indicador } & \multicolumn{5}{|c|}{ Anos } & \multirow{2}{*}{$\begin{array}{c}\text { Variação } \\
\text { entre } 2002 \text { e } \\
2006 \\
\end{array}$} \\
\hline & 2002 & 2003 & 2004 & 2005 & 2006 & \\
\hline $\begin{array}{l}\% \text { de escolas que funcionam em prédio } \\
\text { escolar }\end{array}$ & 87,92 & 88,81 & 89,43 & 90,01 & 90,53 & 2,97 \\
\hline $\begin{array}{l}\text { \% de professores com superior completo } \\
\text { (licenciatura) nas séries iniciais do ensino } \\
\text { fundamental }\end{array}$ & 26,38 & 31,77 & 36,64 & 43,12 & 52,67 & 99,68 \\
\hline $\begin{array}{l}\% \text { de matrículas de } 5^{\mathrm{a}} \text { a } 8^{\mathrm{a}} \text { séries do ensino } \\
\text { fundamental sobre o número total de } \\
\text { matrículas nesse nível de ensino }\end{array}$ & 44,86 & 45,06 & 44,80 & 44,94 & 44,90 & 0,08 \\
\hline
\end{tabular}

Fonte: Censo Escolar - MEC/Inep.

Tabela 2 - Evolução dos Indicadores Educacionais - 2002-2006 - População Indígena

\begin{tabular}{|c|c|c|c|c|c|c|}
\hline \multirow{2}{*}{ Indicador } & \multicolumn{5}{|c|}{ Anos } & \multirow{2}{*}{$\begin{array}{c}\text { Variação entre } \\
2002 \text { e } 2006\end{array}$} \\
\hline & 2002 & 2003 & 2004 & 2005 & 2006 & \\
\hline $\begin{array}{l}\% \text { de escolas que funcionam em prédio } \\
\text { escolar }\end{array}$ & 64,15 & 64,84 & 64,94 & 65,84 & 67,15 & 4,67 \\
\hline $\begin{array}{l}\% \text { de professores com superior completo } \\
\text { (licenciatura) nas séries iniciais do ensino } \\
\text { fundamental }\end{array}$ & 4,02 & 4,29 & 3,67 & 6,15 & 8,53 & 112,38 \\
\hline $\begin{array}{l}\text { \% de matrículas de } 5^{\mathrm{a}} \text { a } 8^{\mathrm{a}} \text { séries do } \\
\text { ensino fundamental sobre o número } \\
\text { total de matrículas nesse nível de ensino }\end{array}$ & 16,84 & 18,28 & 16,26 & 18,75 & 21,23 & 26,12 \\
\hline
\end{tabular}

Fonte: Censo Escolar - MEC/Inep. 
dos professores de escolas indígenas. No que tange à porcentagem de matrículas de $5^{\mathrm{a}}$ a $8^{\mathrm{a}}$ séries do ensino fundamental em relação ao número total de matrículas nesse nível de ensino essa proporção chega a 44,9\% em 2006, enquanto para a população indígena esse indicador não passa de $21,2 \%$.

De forma geral, se olharmos somente os dois anos extremos analisados, isto é, 2002 e 2006, concluímos que a situação educacional do grupo indígena tem apresentado evoluçáo positiva. Merece destaque o aumento da porcentagem de professores, nas séries iniciais do ensino fundamental, com ensino superior completo (licenciatura), que passou de 4,02\% em 2002 para 8,53\% em 2006, um expressivo aumento de $112,3 \%$.

\subsection{O Índice de Igualdade da Educação no Campo (II-EC)}

Embora ainda haja grande disparidade educacional entre o campo e a média brasileira (com o II-EC atingindo 0,493 em 2006), analisando a evolução desse indicador constata-se uma trajetória de redução dessa desigualdade.

Entre 2002 e 2006, o II-EC cresceu 13,2\%, passando de 0,435 para 0,493 (Gráfico 3). O aumento do índice foi contínuo durante o período, com desaceleração

Gráfico 3 - Evolução do Índice de Igualdade da

Educação no Campo - Brasil, 2002-2006

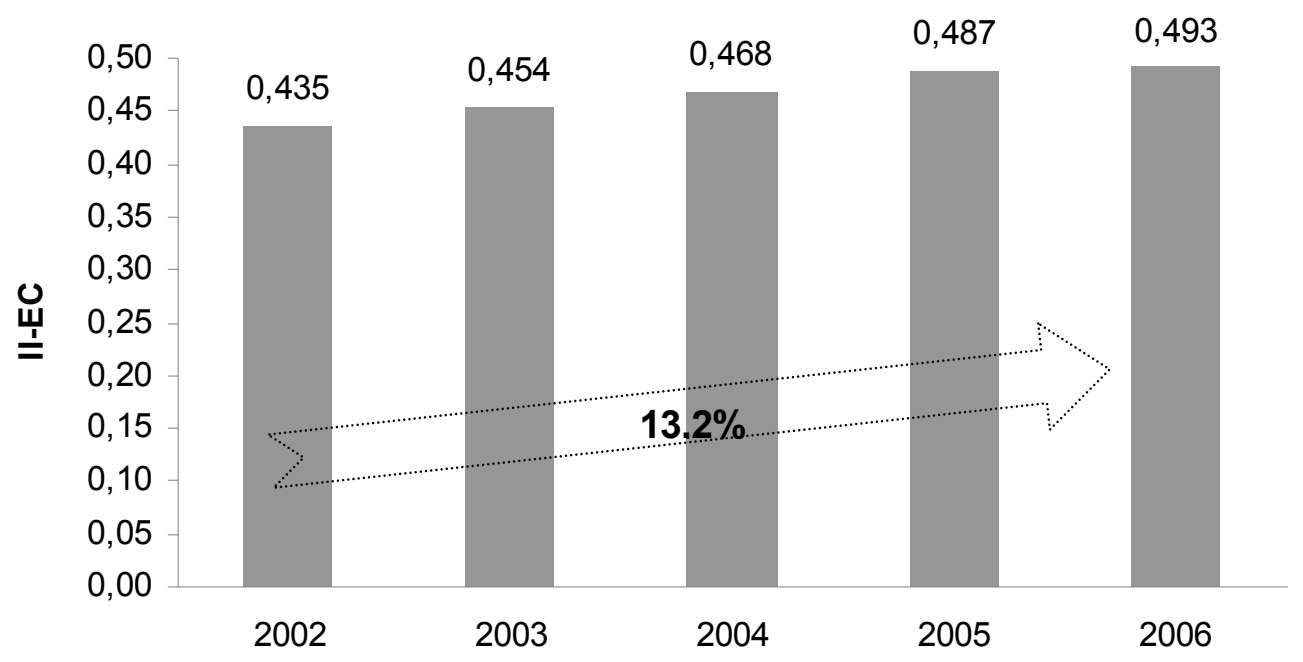

Fonte: Pnad/IBGE. 
da tendência de 2005 para 2006. Apesar desse avanço, o índice alcança menos da metade do ideal de perfeita igualdade entre as condiçóes educacionais da área rural e da média brasileira.

Analisando o gráfico 4, podemos perceber que o componente do índice que mais contribuiu para o seu crescimento, no período em questão, foi a porcentagem de jovens de 18 a 24 anos em áreas rurais que freqüentam o ensino superior em comparação com a média brasileira. No entanto, devemos contextualizar esse crescimento (cerca de 54\% de 2002 a 2006), uma vez que ele se dá em cima de um referencial bastante tímido: apenas 1,6\% dos jovens de 18 a 24 anos residentes em áreas rurais freqüentavam o ensino superior em 2002 (Tabela 4), enquanto cerca de 10\% dos jovens brasileiros dessa faixa etária freqüentavam tal nível de ensino (Tabela 3). Ou

Gráfico 4 - Evolução dos componentes do Índice de Igualdade da Educação no Campo - Brasil, 2002-2006

Escolaridade média (25 anos e mais) em áreas rurais

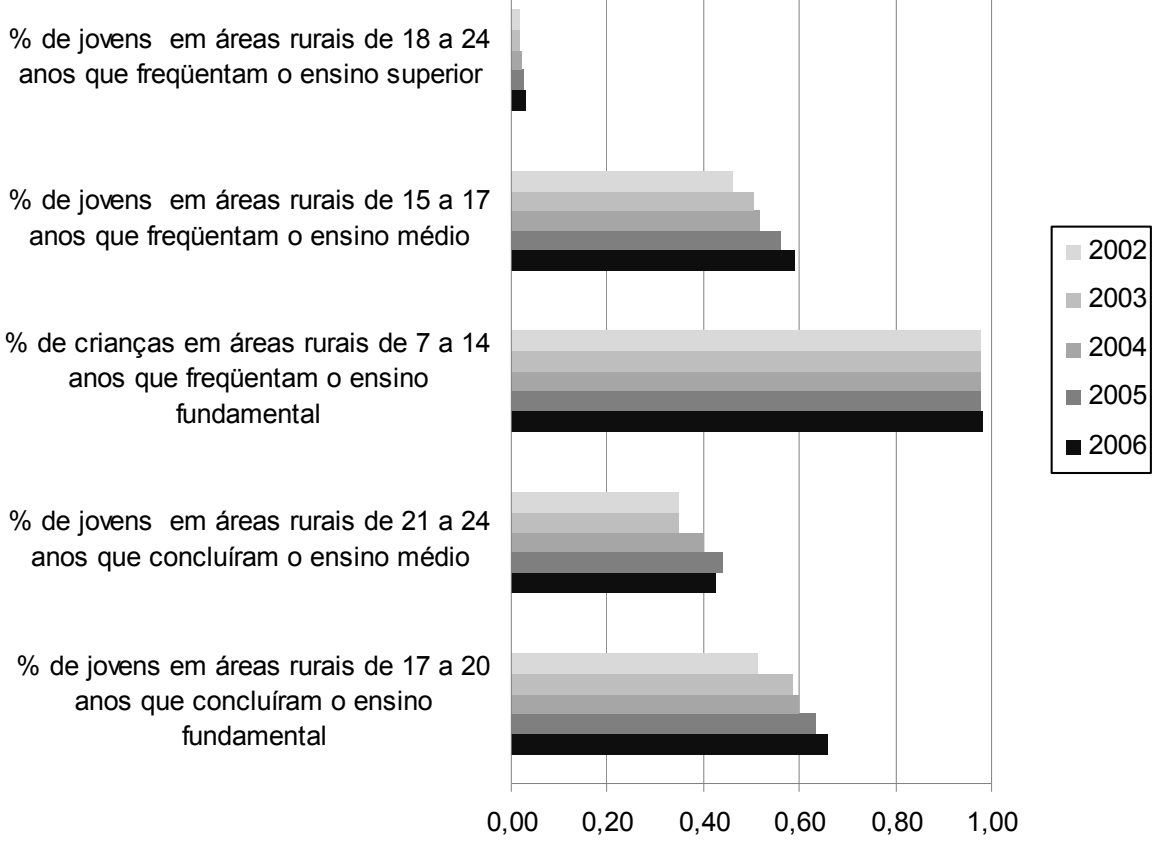


seja, apesar do crescimento expressivo desse indicador, muito ainda dever ser feito para que a igualdade entre cidade e campo, nesse aspecto, seja alcançada.

Outros componentes que apresentaram crescimento significativo no período foram: porcentagem de jovens de 17 a 20 anos em áreas rurais que concluíram o ensino fundamental (aumento de 28,7\%), porcentagem de jovens de 15 a 17 anos que freqüentam o ensino médio (aumento de $28 \%$ ) e a porcentagem de jovens de 21 a 24 anos que concluíram o ensino médio (23\% de aumento). Esses resultados demonstram nítida melhoria no progresso escolar na área rural apesar de os indicadores educacionais ainda se encontrarem em patamares baixos e distantes do ideal. O componente "porcentagem de crianças de 7 a 14 anos que freqüentam o ensino fundamental" aumentou pouco no período (0,4\%), o que pode ser explicado pelo espaço relativamente pequeno para o crescimento desse indicador (que em 2002 já apresentava uma abrangência de $92 \%$ na área rural e de $94 \%$ para a populaçáo brasileira). Finalmente, o componente "escolaridade média" caiu entre 2002 e 2006, não pelo fato de ter havido um decréscimo na média da área rural, mas porque esse crescimento foi inferior ao nacional.

Tabela 3 - Evolução dos Indicadores Educacionais - 2002-2006 - População Total

\begin{tabular}{lcccccc}
\hline \multicolumn{1}{c}{ Indicador } & \multicolumn{5}{c}{ Anos } & Variação entre \\
\cline { 2 - 6 } & $\mathbf{2 0 0 2}$ & $\mathbf{2 0 0 3}$ & $\mathbf{2 0 0 4}$ & $\mathbf{2 0 0 5}$ & $\mathbf{2 0 0 6}$ & 2002 e 2006 \\
\hline $\begin{array}{l}\text { \% de jovens de 17 a 20 anos que } \\
\text { concluíram o ensino fundamental }\end{array}$ & 61,51 & 64,89 & 67,91 & 69,40 & 71,71 & 16,58 \\
\hline $\begin{array}{l}\text { \% de jovens de 21 a 24 anos que } \\
\text { concluíram o ensino médio }\end{array}$ & 41,32 & 45,50 & 47,61 & 50,40 & 52,80 & 27,79 \\
\hline $\begin{array}{l}\text { \% de crianças de 7 a 14 anos que } \\
\text { freqüentam o ensino fundamental }\end{array}$ & 93,68 & 93,79 & 93,93 & 94,52 & 94,91 & 1,31 \\
\hline $\begin{array}{l}\text { \% de jovens de 15 a 17 anos que } \\
\text { freqüentam o ensino médio }\end{array}$ & 40,04 & 43,11 & 45,05 & 45,95 & 47,82 & 19,45 \\
\hline $\begin{array}{l}\text { \% de jovens de 18 a 24 anos que } \\
\begin{array}{l}\text { concluíram o ensino médio, ou que } \\
\text { freqüentam a escola, ou estão na PEA }\end{array}\end{array}$ & 88,91 & 89,46 & 90,15 & 90,55 & 90,56 & 1,85 \\
\hline $\begin{array}{l}\text { \% de jovens de 18 a 24 anos que } \\
\text { freqüentam o ensino superior }\end{array}$ & 9,93 & 10,78 & 10,82 & 11,53 & 12,92 & 30,17 \\
\hline \begin{tabular}{l} 
Escolaridade média (25 anos e mais) \\
\hline
\end{tabular} & 6,13 & 6,28 & 6,43 & 6,56 & 6,78 & 10,63 \\
\hline
\end{tabular}

Fonte: Pnad/IBGE. 
Tabela 4 - Evolução dos Indicadores Educacionais 2002-2006 - População do Campo

\begin{tabular}{|c|c|c|c|c|c|c|}
\hline \multirow{2}{*}{ Indicador } & \multicolumn{5}{|c|}{ Anos } & \multirow{2}{*}{$\begin{array}{c}\text { Variação } \\
\text { entre } 2002 \text { e } \\
2006 \\
\end{array}$} \\
\hline & 2002 & 2003 & 2004 & 2005 & 2006 & \\
\hline $\begin{array}{l}\text { \% de jovens em áreas rurais de } 17 \text { a } 20 \\
\text { anos que concluíram o ensino } \\
\text { fundamental }\end{array}$ & 31,47 & 38,15 & 40,67 & 43,97 & 47,20 & 50,01 \\
\hline $\begin{array}{l}\text { \% de jovens em áreas rurais de } 21 \text { a } 24 \\
\text { anos que concluíram o ensino médio }\end{array}$ & 14,37 & 15,93 & 19,13 & 22,19 & 22,60 & 57,29 \\
\hline $\begin{array}{l}\text { \% de crianças em áreas rurais de } 7 \text { a } 14 \\
\text { anos que freqüentam o ensino } \\
\text { fundamental }\end{array}$ & 91,62 & 91,65 & 91,79 & 92,52 & 93,18 & 1,71 \\
\hline $\begin{array}{l}\% \text { de jovens em áreas rurais de } 15 \text { a } 17 \\
\text { anos que freqüentam o ensino médio }\end{array}$ & 18,50 & 21,71 & 23,30 & 25,73 & 28,29 & 52,91 \\
\hline $\begin{array}{l}\text { \% de jovens em áreas rurais de } 18 \text { a } 24 \\
\text { anos que freqüentam o ensino superior }\end{array}$ & 1,63 & 1,55 & 1,76 & 2,29 & 2,55 & 56,47 \\
\hline $\begin{array}{l}\text { Escolaridade média ( } 25 \text { anos e mais) em } \\
\text { áreas rurais }\end{array}$ & 2,92 & 3,08 & 3,17 & 3,28 & 3,47 & 18,96 \\
\hline
\end{tabular}

Fonte: Pnad/IBGE.

\subsection{O Índice de Igualdade das Açóes Educacionais Complementares (II- AEC)}

O II-AEC evolui, no período analisado, 7,1\% (Gráfico 5). No entanto, pelo valor apontado em $2006(0,604)$, percebe-se ainda um grande espaço para melhoria nesse indicador, para que haja convergência das oportunidades educacionais entre a população em situação de vulnerabilidade e a população brasileira como um todo.

Dentre os componentes do II-AEC (Gráfico 6), os que mais contribuíram para o aumento do índice foram a porcentagem de jovens pobres de 18 a 24 anos que freqüentam o ensino superior, com aumento de $20,2 \%$ no período; a porcentagem de jovens pobres de 15 a 17 anos que freqüentam o ensino médio (19,5\% de crescimento); e a porcentagem de jovens pobres de 21 a 24 anos que concluíram o ensino médio (aumento de 19,4\%). Entre os destaques negativos, o componente porcentagem de jovens pobres de 18 a 24 anos que concluíram o ensino médio, ou que freqüentam a escola, ou estáo na PEA apresentou um decréscimo de $2,6 \%$, enquanto a porcentagem de crianças pobres de 7 a 14 anos que freqüentam o ensino fundamental praticamente não apresentou variação no período. 
Gráfico 5 - Evolução do Índice de Igualdade das Ações Educacionais Complementares - Brasil, 2002-2006

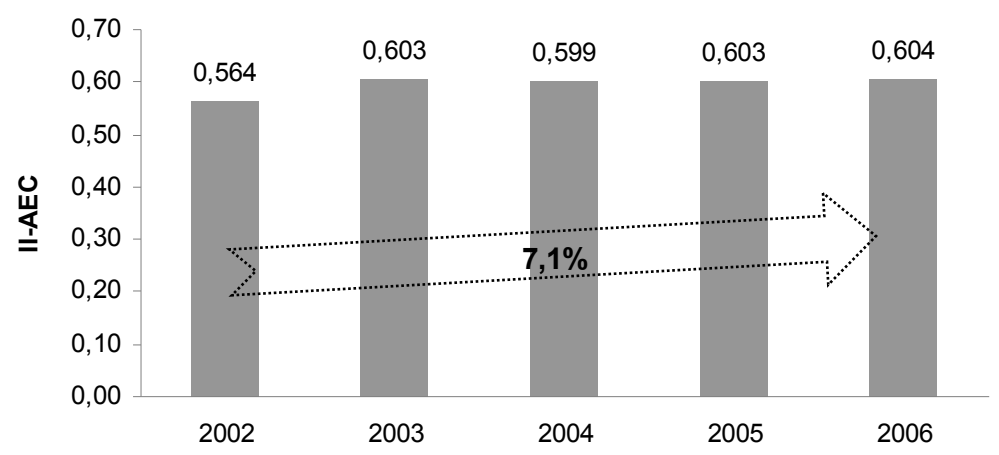

Fonte: Pnad/IBGE.

Gráfico 6 - Evolução dos componentes do Índice de lgualdade das Ações Educacionais Complementares - Brasil, 2002-2006

Escolaridade média (25 anos e mais) dos pobres

$\%$ de jovens pobres de 18 a 24 anos que freqüentam o ensino superior

$\%$ de jovens pobres de 18 a 24 anos que concluíram o ensino médio, ou que freqüentam a escola, ou estão na PEA $\%$ de jovens pobres de 15 a 17 anos
que freqüentam o ensino médio

$\%$ de crianças pobres de 7 a 14 anos que freqüentam o ensino fundamental

$\%$ de jovens pobres de 21 a 24 anos que concluíram o ensino médio

$\%$ de jovens pobres de 17 a 20 anos que concluíram o ensino fundamental

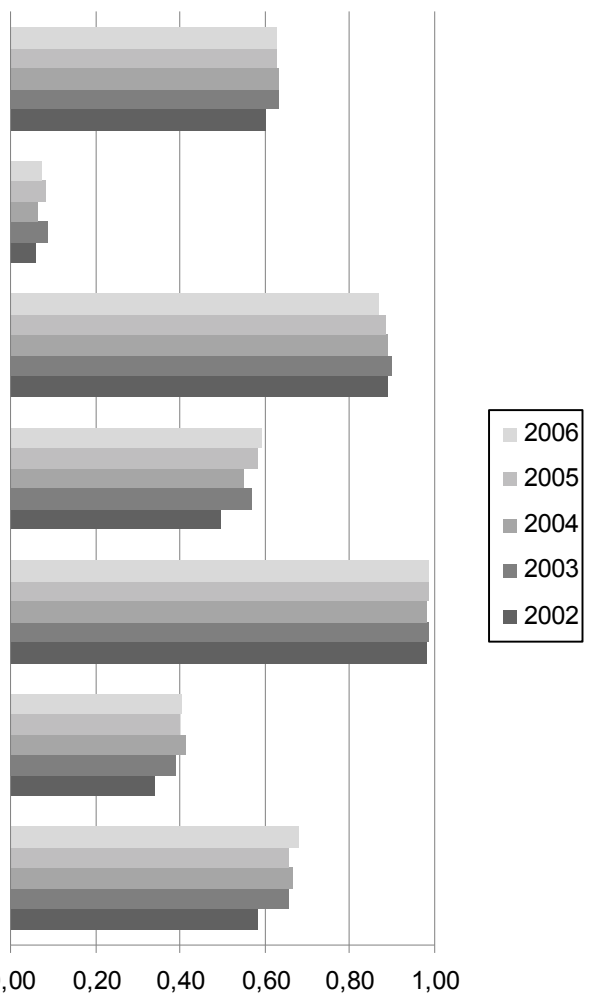

Fonte: Pnad/IBGE. 
Observando a tabela 5, constata-se que a porcentagem de jovens pobres de 18 a 24 anos que freqüentam o ensino superior evoluiu de 0,59\% em 2002 para 0,92\% em 2006, um aumento de 56,5\%. Para a população em geral (Tabela 3), este indicador subiu de $9,9 \%$ para $12,9 \%$, um aumento de $30,2 \%$. A porcentagem de jovens pobres de 15 a 17 anos que freqüentam o ensino médio aumentou de 19,8\% em 2002 para 28,3\% em 2006, variação de 42,7\%. Na população brasileira, esse indicador cresceu 19,5\% de 2002 a 2006 (passou de 40\% para 47,8\%). Outro indicador com evoluçáo positiva, porcentagem de jovens pobres de 21 a 24 anos que concluíram o ensino médio, apresentou variação de $52,6 \%$ no período. Para a população total, a variação desse indicador foi de $27,8 \%$.

Com relação à porcentagem de jovens pobres de 18 a 24 anos que concluíram o ensino médio, ou que freqüentam a escola, ou estáo na PEA a variação negativa chegou a - $0,74 \%$ no período, passando de 79\% em 2002 para 78,5\% em 2006. Esse indicador é preocupante, visto que mais de $20 \%$ dos jovens dessa faixa etária não

Tabela 5 - Evolução dos Indicadores Educacionais - 2002-2006 - População Pobre

\begin{tabular}{|c|c|c|c|c|c|c|}
\hline \multirow{2}{*}{ Indicador } & \multicolumn{5}{|c|}{ Anos } & \multirow{2}{*}{$\begin{array}{c}\text { Variação } \\
\text { entre } 2002 \text { e } \\
2006\end{array}$} \\
\hline & 2002 & 2003 & 2004 & 2005 & 2006 & \\
\hline $\begin{array}{l}\% \text { de jovens pobres de } 17 \text { a } 20 \text { anos } \\
\text { que concluíram o ensino fundamental }\end{array}$ & 35,84 & 42,64 & 45,20 & 45,48 & 48,79 & 36,14 \\
\hline $\begin{array}{l}\% \text { de jovens pobres de } 21 \text { a } 24 \text { anos } \\
\text { que concluíram o ensino médio }\end{array}$ & 13,96 & 17,76 & 19,71 & 20,00 & 21,30 & 52,64 \\
\hline $\begin{array}{l}\% \text { de crianças pobres de } 7 \text { a } 14 \text { anos } \\
\text { que freqüentam o ensino fundamental }\end{array}$ & 92,06 & 92,46 & 92,33 & 93,06 & 93,61 & 1,67 \\
\hline $\begin{array}{l}\% \text { de jovens pobres de } 15 \text { a } 17 \text { anos } \\
\text { que freqüentam o ensino médio }\end{array}$ & 19,83 & 24,53 & 24,77 & 26,84 & 28,29 & 42,71 \\
\hline $\begin{array}{l}\text { \% de jovens pobres de } 18 \text { a } 24 \text { anos } \\
\text { que concluíram o ensino médio, ou que } \\
\text { freqüentam a escola, ou estão na PEA }\end{array}$ & 79,05 & 80,47 & 80,17 & 80,30 & 78,46 & $-0,74$ \\
\hline $\begin{array}{l}\% \text { de jovens pobres de } 18 \text { a } 24 \text { anos } \\
\text { que freqüentam o ensino superior }\end{array}$ & 0,59 & 0,95 & 0,68 & 0,96 & 0,92 & 56,50 \\
\hline $\begin{array}{l}\text { Escolaridade média ( } 25 \text { anos e mais) } \\
\text { dos pobres }\end{array}$ & 3,67 & 3,97 & 4,07 & 4,13 & 4,26 & 15,97 \\
\hline
\end{tabular}

Fonte: Pnad/IBGE. 
estudam nem trabalham (e nem sequer concluíram o ensino médio para pleitear melhores colocações no mercado de trabalho). Tal indicador, na população brasileira, saltou de $88,9 \%$ para $90,6 \%$ no período analisado.

\subsection{O Índice de Igualdade da Diversidade Étnico-Racial (II-DER)}

O gráfico 7 mostra a evoluçáo do II-DER de 2002 a 2006. Verifica-se nesse período um crescimento de $7,5 \%$ do índice para o Brasil, que, em 2006, atingiu 0,825 , valor bastante razoável que demonstra uma desigualdade educacional menos acentuada entre a populaçáo negra e a população brasileira como um todo.

Os componentes que mais contribuíram para esse aumento (Gráfico 8) foram: a porcentagem de jovens negros de 18 a 24 anos que freqüentam o ensino superior (alta de cerca de 30\% no período); a porcentagem de jovens negros de 15 a 17 anos que freqüentam o ensino médio, que evolui $13,3 \%$; e a porcentagem de jovens negros de 21 a 24 anos que concluíram o ensino médio, que aumentou 10,3\%. Os indicadores que obtiveram as piores taxas de crescimento foram: a porcentagem de jovens negros de 18 a 24 anos que concluíram o ensino médio, ou que freqüentam a escola, ou estão na PEA (crescimento de apenas 0,2\%) e a porcentagem de crianças negras de 7 a 14 anos que freqüentam o ensino fundamental (crescimento de 0,4\%).

Gráfico 7 - Evolução do Índice de Igualdade da Diversidade Étnico-Racial - Brasil, 2002-2006

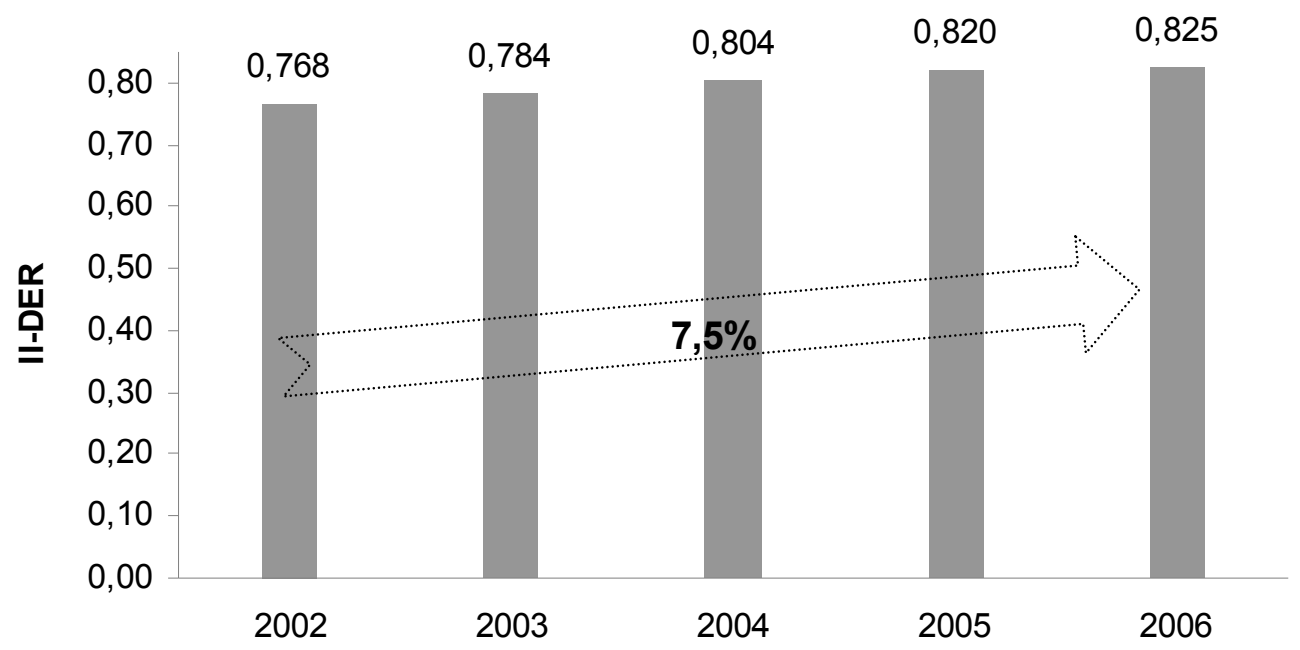

Fonte: Pnad/IBGE. 
Gráfico 8 - Evolução dos componentes do Índice de lgualdade da Diversidade Étnico-Racial - Brasil, 2002-2006

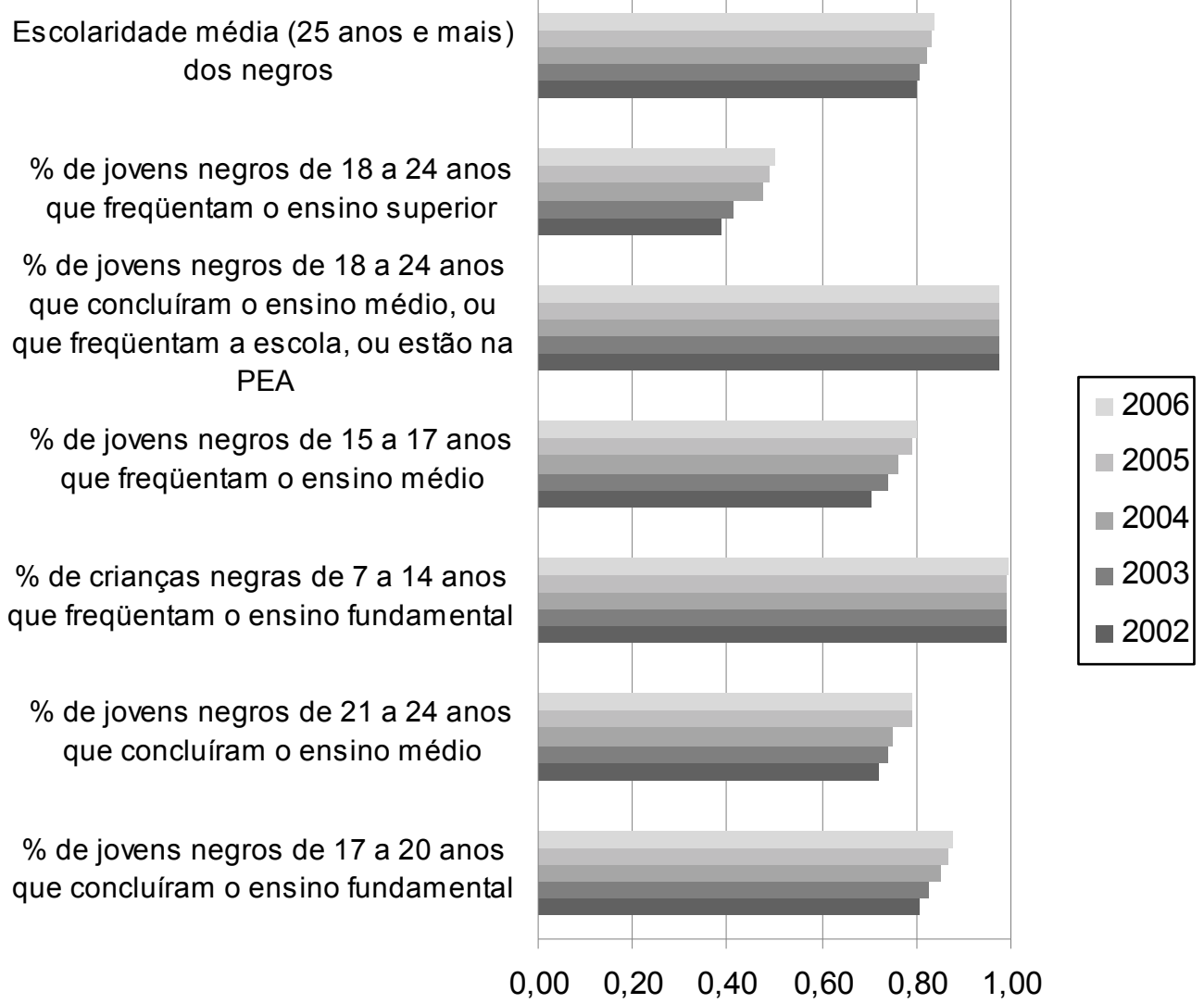

Fonte: Pnad/IBGE.

Aqui, mais uma vez, cabe a ressalva de que, apesar do crescimento, a porcentagem de jovens negros que freqüentam o ensino superior (Tabela 6) atinge patamares ainda muito baixos, com seu valor chegando a $6,5 \%$. A porcentagem de jovens negros que freqüentam o ensino médio alcançou 38,2\% em 2006, e a de jovens negros que concluíram o ensino médio foi de $41,8 \%$ no mesmo ano.

\subsection{O Índice de Igualdade de Gênero para as mulheres (II-Gm)}

O gráfico 9 mostra a evolução do II-Gm de 2002 a 2006 no Brasil. É possível verificar ligeira queda de $0,56 \%$ no valor do índice. O fato a ser destacado, porém, é 
Tabela 6 - Evolução dos Indicadores Educacionais - 2002-2006 - População Negra

\begin{tabular}{|c|c|c|c|c|c|c|}
\hline \multirow{2}{*}{ Indicador } & \multicolumn{5}{|c|}{ Anos } & \multirow{2}{*}{$\begin{array}{c}\text { Variação } \\
\text { entre } 2002 \text { e } \\
2006 \\
\end{array}$} \\
\hline & 2002 & 2003 & 2004 & 2005 & 2006 & \\
\hline $\begin{array}{l}\% \text { de jovens negros de } 17 \text { a } 20 \text { anos que } \\
\text { concluíram o ensino fundamental }\end{array}$ & 49,45 & 53,68 & 57,96 & 60,35 & 63,09 & 27,57 \\
\hline $\begin{array}{l}\% \text { de jovens negros de } 21 \text { a } 24 \text { anos que } \\
\text { concluíram o ensino médio }\end{array}$ & 29,66 & 33,75 & 35,82 & 39,76 & 41,80 & 40,93 \\
\hline $\begin{array}{l}\text { \% de crianças negras de } 7 \text { a } 14 \text { anos que } \\
\text { freqüentam o ensino fundamental }\end{array}$ & 92,70 & 92,75 & 92,84 & 93,74 & 94,26 & 1,68 \\
\hline $\begin{array}{l}\% \text { de jovens negros de } 15 \text { a } 17 \text { anos que } \\
\text { freqüentam o ensino médio }\end{array}$ & 28,22 & 31,92 & 34,31 & 36,31 & 38,19 & 35,33 \\
\hline $\begin{array}{l}\text { \% de jovens negros de } 18 \text { a } 24 \text { anos que } \\
\text { concluíram o ensino médio, ou que } \\
\text { freqüentam a escola, ou estão na PEA }\end{array}$ & 86,53 & 87,15 & 88,06 & 88,45 & 88,34 & 2,09 \\
\hline $\begin{array}{l}\% \text { de jovens negros de } 18 \text { a } 24 \text { anos que } \\
\text { freqüentam o ensino superior }\end{array}$ & 3,84 & 4,45 & 5,13 & 5,67 & 6,49 & 69,05 \\
\hline $\begin{array}{l}\text { Escolaridade média ( } 25 \text { anos e mais) dos } \\
\text { negros }\end{array}$ & 4,89 & 5,05 & 5,28 & 5,44 & 5,66 & 15,63 \\
\hline
\end{tabular}

Fonte: Pnad/IBGE.

o valor apresentado pelo II-Gm brasileiro, de 1,051 em 2006. Tal valor denota que, com base nos indicadores educacionais mensurados, as mulheres possuem melhores condiçóes educacionais, quando comparadas com a população brasileira.

Dentre os componentes do II-Gm (gráfico 10), apenas dois apresentaram evolução positiva no período estudado: a porcentagem de mulheres de 18 a 24 anos que concluíram o ensino médio, ou que freqüentam a escola, ou estão na PEA com $1,8 \%$, e a escolaridade média com leve acréscimo de $0,4 \%$. Os demais tiveram evolução negativa, com maior impacto na porcentagem de mulheres de 21 a 24 anos que concluíram o ensino médio, que caiu $2,5 \%$.

A tabela 7 mostra evoluçáo positiva em todos os indicadores educacionais para as mulheres, com destaque para a freqüência ao ensino superior que apresentou variação de 28,5\%, passando de 11,5\% em 2002 para 14,7\% em 2006. No entanto, a evolução na maioria dos indicadores educacionais para as mulheres ocorreu em ritmo menor ao verificado para a populaçáo brasileira (Tabelas 3 e 7), acarretando taxas de crescimento negativas dos componentes. 
Gráfico 9 - Evolução do Índice de Igualdade de

Gênero para Mulheres - Brasil, 2002-2006

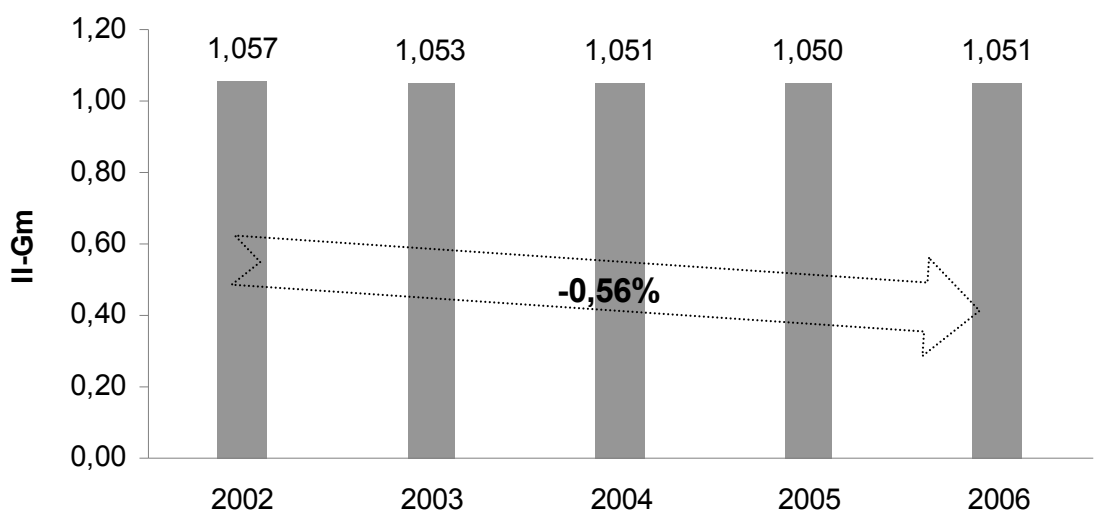

Fonte: Pnad/IBGE.

Gráfico 10 - Evolução dos componentes do Índice de Igualdade de Gênero para Mulheres - Brasil, 2002-2006

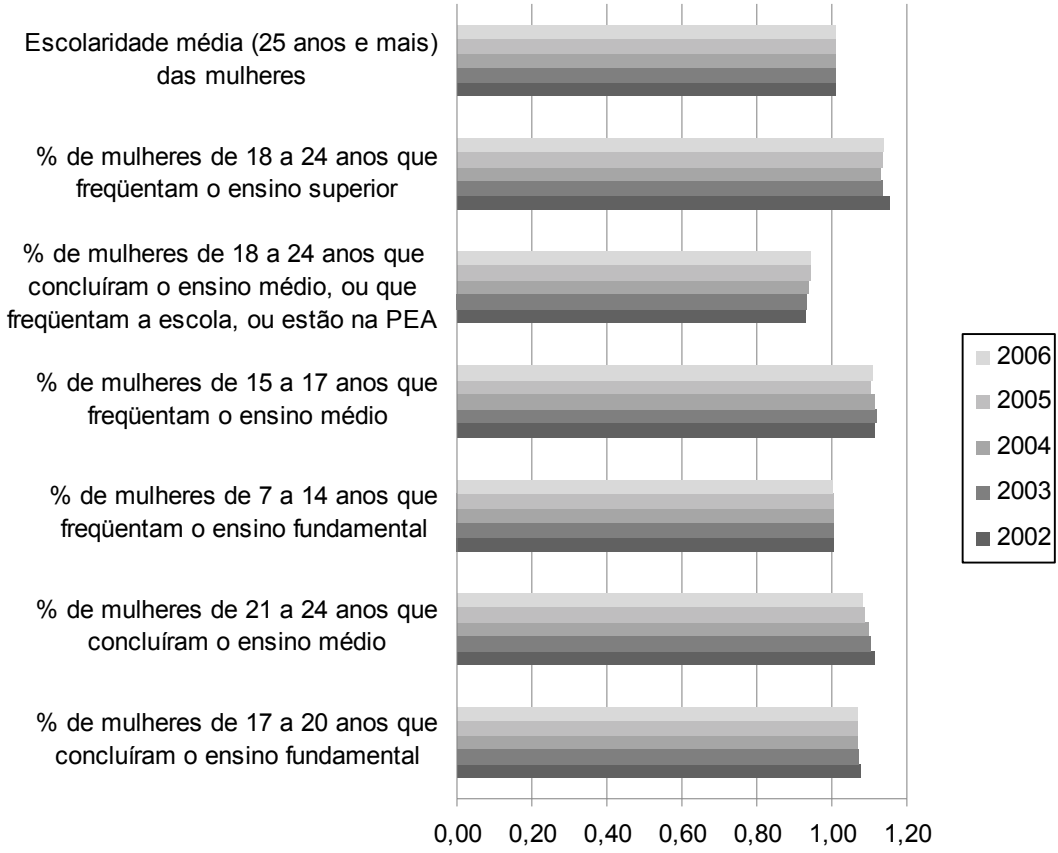

Fonte: Pnad/IBGE. 
Tabela 7 - Evolução dos Indicadores Educacionais - 2002-2006 - Mulheres

\begin{tabular}{|c|c|c|c|c|c|c|}
\hline \multirow{2}{*}{ Indicador } & \multicolumn{5}{|c|}{ Anos } & \multirow{2}{*}{$\begin{array}{c}\text { Variação } \\
\text { entre } 2002 \text { e } \\
2006 \\
\end{array}$} \\
\hline & 2002 & 2003 & 2004 & 2005 & 2006 & \\
\hline $\begin{array}{l}\text { \% de mulheres de } 17 \text { a } 20 \text { anos que } \\
\text { concluíram o ensino fundamental }\end{array}$ & 66,34 & 69,64 & 72,41 & 74,12 & 76,57 & 15,42 \\
\hline $\begin{array}{l}\text { \% de mulheres de } 21 \text { a } 24 \text { anos que } \\
\text { concluíram o ensino médio }\end{array}$ & 45,96 & 50,16 & 52,29 & 54,85 & 57,24 & 24,55 \\
\hline $\begin{array}{l}\% \text { de mulheres de } 7 \text { a } 14 \text { anos que } \\
\text { freqüentam o ensino fundamental }\end{array}$ & 94,06 & 94,19 & 94,26 & 94,79 & 95,00 & 1,00 \\
\hline $\begin{array}{l}\% \text { de mulheres de } 15 \text { a } 17 \text { anos que } \\
\text { freqüentam o ensino médio }\end{array}$ & 44,56 & 48,25 & 50,16 & 50,74 & 52,97 & 18,87 \\
\hline $\begin{array}{l}\text { \% de mulheres de } 18 \text { a } 24 \text { anos que } \\
\text { concluíram o ensino médio, ou que } \\
\text { freqüentam a escola, ou estão na PEA }\end{array}$ & 82,52 & 83,35 & 84,73 & 85,23 & 85,59 & 3,72 \\
\hline $\begin{array}{l}\% \text { de mulheres de } 18 \text { a } 24 \text { anos que } \\
\text { freqüentam o ensino superior }\end{array}$ & 11,45 & 12,20 & 12,20 & 13,09 & 14,71 & 28,45 \\
\hline $\begin{array}{l}\text { Escolaridade média ( } 25 \text { anos e mais) das } \\
\text { mulheres }\end{array}$ & 6,18 & 6,33 & 6,50 & 6,63 & 6,86 & 11,14 \\
\hline
\end{tabular}

Fonte: Pnad/IBGE.

\subsection{O Índice de Igualdade de Gênero para os homens (II-Gh)}

O II-Gh, ao contrário do índice para as mulheres, apresentou leve aumento durante o período estudado para o Brasil (Gráfico 11). Apesar de o índice apontar para a proximidade da igualdade educacional total entre os homens e a populaçáo brasileira (valor de 0,948 em 2006), quando se compara o seu valor com o II-Gm é possível inferir que as mulheres apresentam situação educacional superior à dos homens.

Dentre os componentes do II-Gh (Gráfico 12), destacam-se, por sua contribuição positiva na taxa de crescimento, a porcentagem de homens de 21 a 24 anos que concluíram o ensino médio (alta de 3,2\% no período) e a porcentagem de homens de 18 a 24 anos que freqüentam o ensino superior (crescimento de 1,6\%).

É possível verificar, pela tabela 8 , uma evolução positiva em todos os indicadores educacionais avaliados da populaçáo masculina. Destacam-se a freqüência ao ensino médio e superior e a conclusão do ensino médio, todos com crescimento igual ou superior a $20 \%$. É natural que essa tendência ocorra, uma vez que tais indicadores ainda possuem muito espaço para crescimento, e com a "universalizaçáo" do ensino fundamental a probabilidade do acesso de mais jovens ao ensino médio é maior, em razão da ampliação da base do "funil" do sistema educacional brasileiro. 
Gráfico 11 - Evolução do Índice de Igualdade de Gênero para Homens - Brasil, 2002-2006

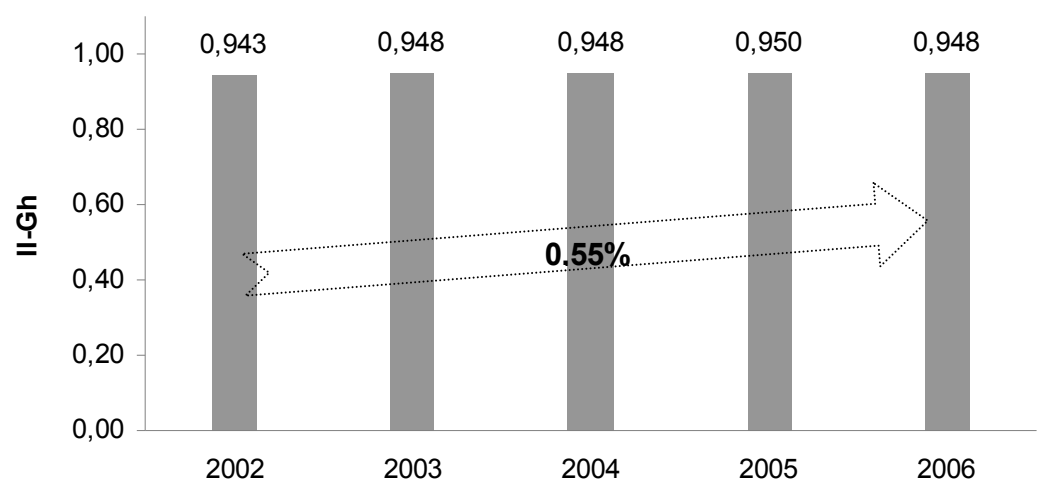

Fonte: Pnad/IBGE.

Gráfico 12 - Evolução dos componentes do Índice de Igualdade de Gênero para Homens - Brasil, 2002-2006 Escolaridade média (25 anos e mais)
dos homens

$\%$ de homens de 18 a 24 anos que freqüentam o ensino superior

$\%$ de homens de 18 a 24 anos que concluíram o ensino médio, ou que freqüentam a escola, ou estão na PEA

$\%$ de homens de 15 a 17 anos que freqüentam o ensino médio

$\%$ de homens de 7 a 14 anos que freqüentam o ensino fundamental

$\%$ de homens de 21 a 24 anos que concluíram o ensino médio

$\%$ de homens de 17 a 20 anos que concluíram o ensino fundamental

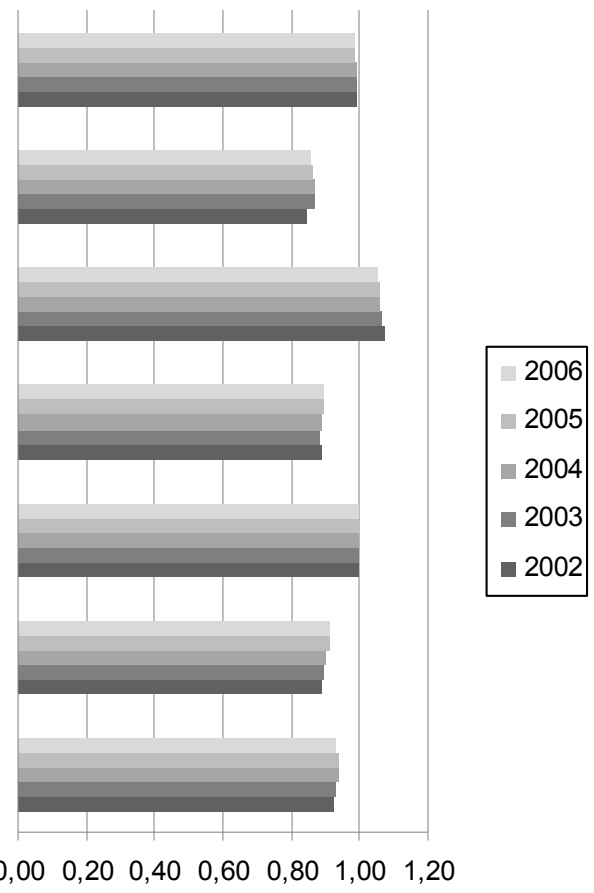

Fonte: Pnad/IBGE. 
Tabela 8 - Evolução dos Indicadores Educacionais - 2002-2006 - Homens

\begin{tabular}{|c|c|c|c|c|c|c|}
\hline \multirow{2}{*}{ Indicador } & \multicolumn{5}{|c|}{ Anos } & \multirow{2}{*}{$\begin{array}{c}\text { Variação } \\
\text { entre } 2002 \text { e } \\
2006\end{array}$} \\
\hline & 2002 & 2003 & 2004 & 2005 & 2006 & \\
\hline $\begin{array}{l}\text { \% de homens de } 17 \text { a } 20 \text { anos que } \\
\text { concluíram o ensino fundamental }\end{array}$ & 56,75 & 60,31 & 63,49 & 64,82 & 66,80 & 17,70 \\
\hline $\begin{array}{l}\% \text { de homens de } 21 \text { a } 24 \text { anos que } \\
\text { concluíram o ensino médio }\end{array}$ & 36,62 & 40,81 & 42,76 & 45,95 & 48,29 & 31,87 \\
\hline $\begin{array}{l}\% \text { de homens de } 7 \text { a } 14 \text { anos que } \\
\text { freqüentam o ensino fundamental }\end{array}$ & 93,31 & 93,41 & 93,61 & 94,25 & 94,82 & 1,61 \\
\hline $\begin{array}{l}\% \text { de homens de } 15 \text { a } 17 \text { anos que } \\
\text { freqüentam o ensino médio }\end{array}$ & 35,58 & 38,12 & 40,07 & 41,21 & 42,69 & 20,00 \\
\hline $\begin{array}{l}\text { \% de homens de } 18 \text { a } 24 \text { anos que } \\
\text { concluíram o ensino médio, ou que } \\
\text { freqüentam a escola, ou estão na PEA }\end{array}$ & 95,34 & 95,53 & 95,67 & 95,82 & 95,62 & 0,29 \\
\hline $\begin{array}{l}\% \text { de homens de } 18 \text { a } 24 \text { anos que } \\
\text { freqüentam o ensino superior }\end{array}$ & 8,39 & 9,37 & 9,40 & 9,98 & 11,10 & 32,27 \\
\hline $\begin{array}{l}\text { Escolaridade média ( } 25 \text { anos e mais) dos } \\
\text { homens }\end{array}$ & 6,07 & 6,22 & 6,36 & 6,48 & 6,68 & 10,04 \\
\hline
\end{tabular}

Fonte: Pnad/IBGE.

\section{CONSIDERAÇÕES FINAIS}

Sistemas de indicadores podem contemplar em sua estrutura medidas-síntese de dimensóes mais complexas, investigadas por meio de vários indicadores primários mais específicos. Propostas integradas de indicadores sintéticos e sistema de indicadores, com recursos gráficos e visuais - como os apresentados aqui - representam certamente um avanço conceitual e instrumental em relação às formas usuais de disseminação desse tipo de ferramenta de gestão e monitoramento de programas de política social.

Estabelecer um sistema de indicadores que se propóe a medir as desigualdades educacionais vinculadas à diversidade constitui-se em um grande desafio. A Diretoria de Estudos e Acompanhamento de Vulnerabilidades Educacionais, ao aceitar e encarar esse problema, e instituir tal sistema, contribuiu, de forma significativa, para aperfeiçoar os instrumentos de acompanhamento do impacto do programa e a alocação racional e focalizada dos recursos públicos.

Voltando o olhar para os resultados encontrados, percebe-se, de maneira geral, uma evoluçáo gradativa na reduçáo das desigualdades educacionais sob o ponto de vista da diversidade. Enquanto as questóes de gênero e diversidade étnico-racial 
apresentaram resultados para seus respectivos indicadores que os aproxima mais da igualdade com a populaçáo brasileira como um todo, a população indígena, a população de baixa renda e a população do campo ainda possuem um longo caminho, a fim de eliminar as desigualdades educacionais. No entanto, é importante ressaltar que o comportamento dos índices se mostrou heterogêneo entre as regióes e Estados brasileiros, o que sugere medidas diferenciadas e alinhadas com a realidade local.

Ficou evidente também, analisando-se o comportamento dos índices e seus componentes, uma maior contribuição daqueles relacionados à freqüência ao ensino médio e superior e à conclusão do ensino médio. Tal fato pode ser justificado pelos baixos patamares atingidos por essas dimensóes educacionais e pelo efeito de "onda" provocado pela "universalizaçáo" do ensino fundamental.

Finalmente, espera-se que este trabalho contribua para o descortinamento da realidade das desigualdades educacionais brasileiras no que tange à diversidade e possa subsidiar iniciativas que visem ao melhoramento das açóes do Programa 1377 e de outras açóes do governo federal. Alguns passos nesse sentido já começam a se concretizar. Como exemplo, pode-se citar a utilização desse sistema de indicadores na estruturação da pesquisa Diversidade na Educação, desenvolvida pela parceria Secad/Inep, que tem por objetivo aferir o impacto da discriminação (raça/cor, gênero, orientação sexual, etnia, etc.) no acesso, permanência e desempenho dos alunos da educação básica.

\section{REFERÊNCIAS BIBLIOGRÁFICAS}

BLANCO COSSÍO, M. et al. O Sistema de monitoramento e avaliação baseado em resultados (SM\&A-R) para as metas do Programa Educação para a Diversidade e Cidadania. Brasília: MEC/Unesco, 2006. (Coleção Educação para Todos, Série Avaliação, n. 8, v. 25)

JANNUZZI, P. M. Considerações sobre uso, abuso e mau uso de indicadores nas políticas públicas municipais. Revista de Administração Pública, Rio de Janeiro, v.36, n. 1, p. 51-72, 2002.

LATOUR, B. Redes que a razão desconhece: laboratórios, bibliotecas, coleções. In: BARATIN, M.; JACOB, C. O Poder das bibliotecas. Rio de Janeiro: EdUFRJ, 2000. p. 21-44.
RYTEN, J. Should there be a human development Index? Statistique, développement et Dorits de l'Homme Seminar. Montreaux, Setembre, 2000. International Association for Official Statistics.

SALTELLI, A. et al. Composite indicators - the controversy and the way forward. Palermo: OECD World Forum on Key Indicators. 2004. Disponível em: <http://www.oecd.org/ dataoecd/40/50/33841312.doc>. Acesso em: abr. 2008.

SCANDAR NETO, W. J. Síntese que organiza o olhar: uma proposta para construção e representação de indicadores de desenvolvimento sustentável e sua aplicação 
para os municípios fluminenses. Dissertação (Mestrado). Escola Nacional de Ciências Estatísticas, Rio de Janeiro, 2006.

SCANDAR NETO, W. J.; SILVA, P. L. N.; JANNUZZI, P. M. Do que precisam os gestores de programas sociais? Brasília: MEC/Unesco, 2006. (Coleção Educação para Todos, Série Avaliação, n. 8, v. 25)
SOARES, J. F.; ALVES, M. T. G. Desigualdades raciais no sistema brasileiro de educação básica. Educação e Pesquisa, v.29, n.1, p. 147165, 2003.

WORLD BANK. Designing and building a results-based monitoring, and evaluation system: a tool for public sector management. Washington, DC, 2000.

Recebido em: outubro 2008

Aprovado para publicação em: novembro 2008 